\title{
Tail of the Pancreas
}

National Cancer Institute

\section{Source}

National Cancer Institute. Tail of the Pancreas. NCI Thesaurus. Code C12271.

The left extremity of the pancreas within the lienorenal lig ament. 